\title{
Show me the product, show me the model: Effect of picture type on attitudes toward advertising 2 ?
}

\author{
Nilüfer Z. Aydınoğlu ${ }^{\mathrm{a}, *, 1}$, Luca Cian ${ }^{\mathrm{b}, 1}$ \\ ${ }^{a}$ College of Administrative Sciences and Economics, Koç University, Rumelifeneri Yolu, Sartyer, İstanbul 34450, Turkey \\ ${ }^{\mathrm{b}}$ Ross School of Business, University of Michigan, 701 Tappan Avenue, Ann Arbor, MI 48109, United States
}

Received 16 March 2013; received in revised form 24 March 2014; accepted 4 April 2014

Available online 13 April 2014

\begin{abstract}
We suggest that a consideration of consumer self-evaluations is fundamental to understanding the conditions under which it is more advantageous to present person or product pictures in print advertisements. We build on the basic human motives of self-enhancement and selfverification to propose that the specific self-esteem level of consumers, in the domain relevant for the category, differentially affects their responses to picture type. Specifically, for consumers with low (high) domain-specific self-esteem, depicting a product (person) in the advertisement enhances attitudes toward the advertisement more than depicting a person (product). In two studies, we demonstrate the proposed matching relationships using two different domains of consumer self-evaluation: appearance self-esteem and academic self-esteem. We also show that increased and more fluent generation of self-related mental imagery drives the observed improvement in attitudes toward the advertisement. Our findings suggest direct implications for advertising design.
\end{abstract}

(C) 2014 Society for Consumer Psychology. Published by Elsevier Inc. All rights reserved.

Keywords: Advertising effectiveness; Pictures; Self-esteem; Mental imagery

\section{Introduction}

Contemporary print advertising is distinctive in its reliance on the persuasiveness of pictures (McQuarrie, 2007). Pictures have come to occupy an increasingly large portion of the typical magazine or newspaper advertisement (ad), and almost every print ad contains a picture (van Gisbergen, Ketelaar, \& Beentjes, 2004). This reliance is justified given the variety of ways in which pictorial stimuli have been shown to facilitate

it Norbert Schwarz served as the editor on this paper. Authors acknowledge the valuable input of the editor and the reviewers, and would also like to thank colleague Baler Bilgin for his helpful comments.

* Corresponding author.

E-mail addresses: naydinoglu@ku.edu.tr (N.Z. Aydınoğlu), lcian@umich.edu (L. Cian).

${ }^{1}$ Authors contributed equally to the research; author names are in alphabetical order. persuasion and improve related consumer responses (Edell \& Staelin, 1983).

Although attention, learning, memory, and attitude enhancing abilities of pictures are well documented, researchers criticize them as being visuals "imposed" by advertisers (Lutz \& Lutz, 1978). The choice of a specific picture for an ad may limit its potential relevance for some viewers. For instance, an ad for a holiday resort depicting a poolside full of people may conjure a vivid representation of the advertised experience. However, it may seem less personally relevant to some of the viewers who cannot relate to the people depicted in the ad or who may find some aspect of the pool unsuitable for themselves. Such a potentially incongruent representation is especially problematic because a key aspect of advertising effectiveness is the ability to encourage viewers to relate to some aspect of the product and/or the ad (Debevec \& Romeo, 1992). Self-referencing, this process of relating external stimuli to oneself, introduces additional memory and persuasion advantages in an advertising context 
(Meyers-Levy \& Peracchio, 1996). Therefore, factors that encourage self-referencing when processing pictorial stimuli are crucial to study because they may ameliorate the imposed nature of pictures in ads.

In this paper, we consider consumer self-perception as a factor that may affect self-referencing when processing pictures in advertising. We focus on the type of picture used in an ad, and we explore the conditions under which presenting a person versus a product picture is more advantageous. We suggest that the specific consumer self-esteem elicited by the product category (e.g., appearance self-esteem for cosmetic products) affects consumer reaction toward the use of person or product pictures in advertising.

As Yang, Zhang, and Peracchio (2010) note, only a few researchers have examined consumer self-perception as a determining factor in the effectiveness of pictorial stimuli within advertising. An important stream of research on pictures with such a focus has been the study of idealized advertising images in relation to physical self-esteem. Multiple papers have consistently shown the significant role of women's appearance self-esteem in affecting their responses to ads that use pictures of attractive models (e.g., Lockwood \& Kunda, 1997; Martin \& Gentry, 1997). Specifically, women with low appearance self-esteem experienced greater negative affect than women with high appearance self-esteem when exposed to ads containing pictures of beautiful women (e.g., Bower, 2001). This negative affect, in turn, lowered their evaluations of product argumentation and resulted in less favorable attitudes toward the ad (e.g., Martin, Veer, \& Pervan, 2007). This stream of work focuses on the effectiveness of person pictures in advertising, as affected by consumer self-perceptions in the domain of appearance self-esteem.

We aim to take a more basic perspective in this paper. We study product pictures in addition to person pictures. Moreover, we explore their relation to consumer self-perceptions in multiple domains of specific self-esteem: appearance and academic. In both of these domains, the choice of a product picture (i.e., cosmetic products or educational services) versus a person picture (i.e., attractive models or successful models) differentially affects attitudes toward the ad, depending on consumers' specific self-esteem level in the given domain (i.e., domain-specific self-esteem). We posit that the interplay between the types of picture used in an ad and consumers' domain-specific self-esteem triggers greater self-referencing, ultimately affecting attitudes toward the communication.

We add to the existing research on advertising effectiveness in various ways. First, multiple scholars have noted the lack of a conceptual toolkit for differentiating pictures and "breaking up" their elements to understand them better (e.g., McQuarrie, 2007). We identify person versus product pictures as an important conceptual (and strategic) differentiation, which has not been the focus of previous systematic empirical work. This focus also allows us to extend the work on idealized advertising images by incorporating the study of product pictures together with person pictures, using multiple specific self-esteem domains for both male and female consumers. We also demonstrate a process explanation through increased and easier generation of self-related mental imagery, building on self-referencing. Because pictures have been noted previously as having limited capacity to be self-relevant with their advertiser-imposed imagery (Lutz \& Lutz, 1978), our work also adds to research on imagery processing.

We begin by discussing the literature relevant to our research. We present insights from previous work on the imagery value of pictures and consumer self-esteem while building the conceptual framework for our hypothesized effects. We then describe in detail two studies that use appearance and academic self-esteem domains. We conclude by discussing the specific contributions of the research and presenting future directions in this area.

\section{Imagery value of pictures as affected by self-referencing}

Previous research has established the perceptual and persuasive advantages of using pictures in advertising, either in comparison to or through their interaction with textual systems (e.g., Peracchio \& Meyers-Levy, 2005; Scott, 1994; Sojka \& Giese, 2006). Pictures have high attention-grabbing and -keeping qualities (McQuarrie, 2007). They are remembered better (Childers \& Houston, 1984), and they influence attitudes more than words alone (Kisielius \& Sternthal, 1984).

Pictures, due to their vivid nature, are also influential through their imagery value (MacInnis \& Price, 1987). Imagery processing is "a mental event involving visualization of a concept or relationship" (Lutz \& Lutz, 1978), and increased imagery has been consistently shown to improve consumer attitudes toward advertising (e.g., Bolls \& Muehling, 2007; Bone \& Ellen, 1992; Rossiter \& Percy, 1980). Accordingly, researchers have suggested the use of concrete pictures (visuals easily identifiable as a person, place, or object) as an important means of stimulating imagery processing and improving attitudes toward the ad (Babin \& Burns, 1997).

A potential limitation of concrete pictures is that the imagery generation can be restricted to the advertiser-imposed content of the visual (Lutz \& Lutz, 1978). McQuarrie (2007) suggests that the imagery value of a picture should not only be limited to its representational ability of an existing content, but should also incorporate its capacity to stimulate further imagery generation. Accordingly, we posit that to move beyond the imposed or suggested imagery content of concrete pictures, viewers need to be able to relate to some aspect of this content. The imagery value of pictures, and the corresponding positive influence on consumer responses, should improve when greater self-referencing occurs. Knowledge structures about oneself contain rich and plentiful associations, which are also, by definition, more pertinent for the individual (Burns, Biswas, \& Babin, 1993). The effectiveness of a marketing communication improves when viewers are able to tap into these associations about themselves while processing the stimuli (Burnkrant \& Unnava, 1995; MacInnis \& Jaworski, 1989).

Building on this significance of self-referencing, we focus on the activation of self-related imagery through the correct use of pictures in advertising, while considering consumer selfperceptions. Similar to Aydinoglu and Krishna (2012), we define self-related mental imagery as 'consumers' visualization of the 
self in product purchase, trial, or usage situations." Although concrete pictures are representational in nature, we propose that a consideration of domain-specific consumer self-esteem when choosing a particular picture will improve its self-relatedness for the consumers and lead to an easier and increased generation of self-related mental imagery. Our focus is not on general self-esteem, but rather, we are interested in the effect of specific self-esteem, which pertains both to the domain of the product category and to the domain of the picture that illustrates the benefits of the product, as detailed in the next section.

\section{Consumer self-esteem}

Self-esteem is defined as "an individual's self-evaluation (approval or disapproval) and the extent to which the person believes himself worthwhile" (Coopersmith, 1990). Previous research notes the distinction between the "global" and "specific" conceptions of self-esteem. Marsh (1993) emphasizes the multi-dimensionality of the self-concept, claiming that an individual can have different levels of esteem in relation to different domains of self. The global conception of self-esteem ("general self-esteem") assumes a trait-like definition in which an individual's self-esteem levels are relatively stable over time, and is most relevant to psychological well-being (Crandall, 1973). On the other hand, "specific self-esteem" is most relevant to behavior and measures situation- and domain-specific self-evaluations (Rosenberg, Schoenbach, Schooler, \& Rosenberg, 1995). Because we are more interested in exploring the direct attitudinal effects of picture type in an ad (as affected by individual self-esteem levels), our conceptual and methodological focus in this paper is on domain-specific self-esteem, similar to previous work (e.g., Crocker, Luhtanen, Cooper, \& Bouvrette, 2003; Woo \& Frank, 2000).

The need for general and specific self-esteem is often regarded as a core concern of humans (Dijksterhuis, 2004). High self-esteem is a buffer against stress and the experience of failures; and individuals are motivated to maintain and improve their self-esteem (Steele, 1988). Accordingly, research recognizes motivations of self-enhancement (elevating self-evaluations) and self-verification (preserving positive selfevaluations) as central goals of existence (e.g., Allport, 1937; Erikson, 1959). Furthermore, compensatory self-enhancement theory suggests that people with low self-esteem are more motivated to self-enhance than people with higher self-esteem (Swann, Pelham, \& Krull, 1989). People with negative selfviews rarely receive positive self-feedback, and they make compensatory adjustments to improve their self-concept. On the other hand, a desire to verify positive self-evaluations motivates high-self-esteem individuals (Swann \& Pelham, 2002).

In line with the recognized central importance of these two different motivations, we suggest that for a given marketing context, consumers with high versus low levels of domainspecific self-esteem will respond differently to marketing communications. For instance, consumers' appearance selfesteem will influence their responses to ads for cosmetic products; and their academic self-esteem will affect their responses to ads for education-related products. Accordingly, the consideration of domain-specific consumer self-esteem becomes fundamental in the selection of an ad's picture type. For consumers with low domain-specific self-esteem, pictures appealing to self-enhancement motives should be more effective than pictures appealing to self-verification motives. Conversely, for consumers with high domain-specific self-esteem, pictures appealing to self-verification motives should lead to more favorable attitudes toward the ad than pictures appealing to self-enhancement motives.

\section{Picture type}

Most print ads using pictures depict either a visual representation of the specific product being advertised or a person who is presumably a user of the product (Lynch \& Schuler, 1994; Pollay, 1985). The image in ads with product pictures is usually of the product itself. For ads with person pictures, however, the selection of the specific model is yet another consideration. One generalization we make here is that people depicted in advertising portray desirable characteristics in the domain being advertised. For instance, appearancerelated ads would generally use attractive models, and education-related ads would generally use models who convey professional or academic success. This assumption is grounded in Pollay's (1985) observation, in his review of the history of print advertising, that advertising usually constructs a world of hopes and high standards with the objective of selling products to that end. As such, ad models represent the (idealized) result one can obtain by using that product or service.

Building on the reviewed streams of literature, we anticipate that a picture of a (desirable) person is more in line with the selfperceptions of consumers with high levels of domain-specific self-esteem due to their self-verification motives, compared to people with low domain-specific self-esteem. On the other hand, consumers with low levels of domain-specific self-esteem have difficulty relating to the positively portrayed person picture. We suggest that a product appeal will be more congruent with their self-perceptions and motivations, because it does not necessarily indicate self-verification but does suggest means for self-enhancement. We therefore propose the following:

H1. Domain-specific consumer self-esteem level will moderate the effect of type of picture (domain-relevant person/product) on attitudes toward the ad.

\section{More specifically,}

H1a. For consumers with low domain-specific self-esteem, a domain-relevant product picture in an ad will result in more favorable evaluations of the ad than a domain-relevant person picture.

H1b. For consumers with high domain-specific self-esteem, a domain-relevant person picture in an ad will result in more favorable evaluations of the ad than a domain-relevant product picture.

Finally, we suggest that the proposed congruence between the consumer's domain-specific self-esteem and picture type 
increases the potential for self-referencing as consumers can more readily relate to the pictures that match their self-perceptions and motivations. Greater potential for self-referencing suggests an easier and increased generation of mental imagery (Petrova \& Cialdini, 2005). Also, the generated imagery will not be bound by the advertiser-imposed visual and will be self-related in nature, in line with the main tenets of the self-referencing theory (Burns et al., 1993). Research shows that increased imagery processing improves attitudes (e.g., Bone \& Ellen, 1992), and that the ease with which one generates or processes information also results in more favorable evaluations (Schwarz, 2004; Schwarz et al., 1991). Hence, we propose that the effect of picture type on attitudes toward the ad, moderated by viewers' domain-specific self-esteem, occurs through an increase in the extent and ease of self-related mental imagery generated. More formally, we hypothesize the following:

H2. Moderated mediation: Consumers' domain-specific self-esteem level will moderate the effect of picture type (domain-relevant person or product) on the extent and ease of self-related mental imagery generated, which in turn will affect attitudes toward the ad.

Next, we report two studies that test these predictions in two different specific self-esteem domains to establish applicability of our propositions in multiple contexts. Study 1 is focused on appearance self-esteem, and study 2 is focused on academic self-esteem. These domain choices are motivated partly by the attention they have received in previous research (Crocker et al., 2003; Martin \& Gentry, 1997), giving us the opportunity to use established measurement scales and procedures. Also, these specific domains provide relevant product categories that can be used within study design, as detailed below. In line with its domain focus on appearance self-esteem, study 1 uses only female subjects because research shows physical esteem is more important for women than for men (Rosen \& Gross, 1987). This practice of focusing on female subjects is also typical in previous research that uses appearance-related product categories for stimuli design (e.g., Martin \& Gentry, 1997). Study 2 uses both male and female participants, as allowed by its focus on the academic self-esteem domain. In terms of the proposed process explanation, study 1 focuses on the "extent" of self-related imagery generated and study 2 focuses on the "ease" with which it is generated, with the aim of presenting complementary support for the proposition.

\section{Study 1: Appearance self-esteem and picture type}

The domain focus of study 1, appearance self-esteem, relates to feelings of self-worth in terms of physical appearance and attractiveness (Heartherton \& Polivy, 1991). Research has recognized body image and physical esteem as an important source of general self-esteem, especially for women (Rosen \& Gross, 1987). Within this domain, study 1 focuses on an appearance-related product category, and tests how the type of domain-specific picture used in the ad (product vs. person) interacts with consumer appearance self-esteem in affecting consumer attitudes toward the ad (H1). The study also serves as a demonstration of the proposed process through the generation of self-related mental imagery with a moderated mediation model (H2).

Our conceptualization suggests the following specific expectation: in the context of a beauty product, an ad depicting an attractive model (instead of the product) is preferred by people who like their own appearance (high appearance self-esteem). On the other hand, an ad using a picture of the product (instead of a picture of the model) is preferred by people who do not have a high evaluation of their appearance (low appearance self-esteem). Those who have a lower opinion of their appearance have more difficulty imagining themselves as turning into the beauty represented by the model in the picture even if they used the product, and this imagery difficulty adversely affects attitudes toward the ad.

Because our hypotheses are qualified by domain relevance, we ran two pretests to pick a relevant product category and choose specific stimuli. We first present the pretests and explain the stimuli, and then continue with the main experiment.

\section{Pretests and stimuli}

\section{Pretest 1 - domain-relevant category}

We first ran a pretest to pick a relevant product category for the specific domain of appearance self-esteem. Forty-eight female participants, recruited from an online pool, rated the relevance of four different product categories (moisturizers, teeth-whitening strips, sunglasses, and perfumes) for physical appearance and attractiveness, using a three-item scale developed specifically for the domain ( $\alpha=.93$; see Appendix 1 for the items). A repeated-measures analysis of variance test revealed a significant effect of product category on perceived relevance $(F(3,141)=$ 15.53; $p<.01)$. Planned contrasts between product categories showed that teeth-whitening strips had the highest perceived relevance $\left(M_{\text {TeethWhitening }}=5.08\right)$, significantly greater than the overall mean of the other three categories $(F(1,47)=33.01$; $p<.01)$, and directionally larger than the second-highest rated category $\left(M_{\text {Moisturizer }}=4.77\right)$. Therefore, we chose teeth-whitening strips as the focus of the study for stimuli creation.

\section{Pretest 2 - stimuli}

We ran a second pretest to select the specific ad stimuli to be used in the main experiment, which would be perceived as realistic and relevant for the domain. We created multiple basic print ads for a teeth-whitening product with the fictitious brand name Dentex. The ads included product category name, brand name, and a picture depicting a product or a female model. We created five versions of the ad for both the product and person conditions, each with different visuals. We recruited fifty-four participants from an online pool for the pretest. Each participant saw five different versions of the ad (either with product or person pictures) in a randomized order, and rated each one on its relevance, realism, picture familiarity, and picture attractiveness (see Appendix 1 for the items). 
Results revealed three person and three product pictures with higher ratings of realism and relevance for the domain compared to other stimuli in the corresponding picture-type conditions $\left(p^{\prime} \mathrm{s}<.1\right.$; see Appendix 2a for the selected stimuli and Appendix 3a for means). We wanted to control for viewers' familiarity with the selected pictures to rule out possible confounding effects of novelty or fluency. Establishing that any person or product picture was not evaluated particularly high or low in terms of perceived attractiveness was also important, in line with our domain-specific conceptualization. Further analyses showed no discernible differences among the six chosen stimuli on realism, relevance, familiarity, and perceived attractiveness ( $p$ 's $>.2$; see Appendix $3 \mathrm{a}$ for means). The selection of multiple stimuli for each condition of the key independent variable in the main experiment ( 3 versions of product and person pictures each) will enable us to rule out other possible confounds due to the idiosyncrasies of the individual visuals.

\section{Main experiment}

\section{Design}

Based on the results of the pretests, study 1 compared multiple versions of a print ad for a teeth-whitening brand Dentex in terms of effectiveness on attitudes toward the ad, as affected by the level of the viewer's appearance self-esteem. Accordingly, the study used a between-subjects manipulation of picture type (product vs. person) as the key independent variable. Picture version (A vs. B vs. C; see Appendix 2) was the second between-subjects factor, which was nested in picture type as a random sub-group. The design also included respondents' appearance self-esteem levels as a measured continuous variable.

\section{Procedure and measures}

One hundred and sixty-seven female participants completed the experiment from an online pool. Participants were told that the study included multiple short surveys from different research projects. The measure of appearance self-esteem was taken randomly before or after the main ad-evaluation task, using the six-item scale developed by Heartherton and Polivy $(1991 ; \alpha=$ .90; 7-point scale). When this measure was presented first, we included an eight-minute filler task between the two sections.

As the main task, participants saw one of the randomly assigned six print ads. We told them that this ad was designed for Dentex, a new teeth-whitening brand, and that they should review the ad carefully in order to respond to a series of questions about the ad afterward. After viewing the ad, participants first indicated their attitudes toward the ad, which was measured using a five-item scale with four semantic differential questions (good/ bad; strong/weak; pleasant/unpleasant; appealing/unappealing) and one question rating agreement with the statement "this ad was very effective as a whole" on seven-point scales $(\alpha=.96)$. Next, participants rated the extent of self-related mental imagery that they experienced while reviewing the ad, using a four-item scale developed to reflect domain-specific self-related imagery. Accordingly, they indicated their agreement with the following statements on a seven-point scale: "I visually imagined myself using or trying the product;" "I visually imagined myself shopping for this product;" "I visually imagined how I would look after using this product;" "I imagined what it would be like to use this product" $(\alpha=.93)$.

Finally, we collected their responses on control questions to rule out alternative explanations, which are discussed below. We also asked participants about the purpose of the study, and none guessed the connection between the self-esteem measurement and the main task.

\section{Results and discussion}

We first conducted a nested ANCOVA on our key dependent variable, attitudes toward the ad, with picture type (product vs. person) as the independent variable, picture version (A vs. B vs. C) as the nested factor (within picture type), and respondent appearance self-esteem level and order of self-esteem measurement as the covariates. This nested analysis allowed us to examine whether participants' responses varied across the different picture versions within the product and person-picture conditions. Although we have no specific hypotheses regarding the main effects of picture type and appearance self-esteem, we expect the nested factor, picture version, to be insignificant in order to rule out possible unforeseen effects related to the idiosyncrasies of specific pictures.

The main effect of picture type was not significant $(p>.2)$. We observed a significant main effect of appearance self-esteem on attitudes toward the ad $(F(1,159)=13.70 ; p<.01$; see Fig. 1 for the data pattern), which was not foreseen but does not contradict our predictions. Furthermore, the main effect of picture version, as nested factor in picture type, was not significant $(p>.2)$, indicating that participants' evaluations did not vary across the different versions of the pictures within picture-type conditions. The final covariate, measurement order, was also not significant $(p>.8)$.

Next, to test for the hypothesized interaction between picture type and appearance self-esteem level (H1) and to check for the "directional" predictions of this moderation hypothesis (H1a and H1b), we followed the guidelines provided by Spiller, Fitzsimons, Lynch, and McClelland (2013) and used the Johnson and Neyman (1936) technique (see also Bauer \& Curran, 2005; Hayes \& Matthes, 2009). The technique enabled us to identify the regions of the moderator where the effect of the independent variable (product vs. person picture) turns from non-significance to significance. We could also observe the mean values of the dependent variable estimated for various intervals of the moderator as affected by the independent variable.

The Johnson-Neyman technique showed two significant regions for the effect of the independent variable on attitudes toward the ad: for appearance self-esteem values below 3.12 and above 4.40. In other words, when appearance self-esteem was low (below 3.12), the product picture resulted in significantly more favorable attitudes, as reflected by the data pattern in Fig. 1, compared to a person picture (with confidence intervals, CI, between .82 and .80 ), but not when appearance self-esteem was 


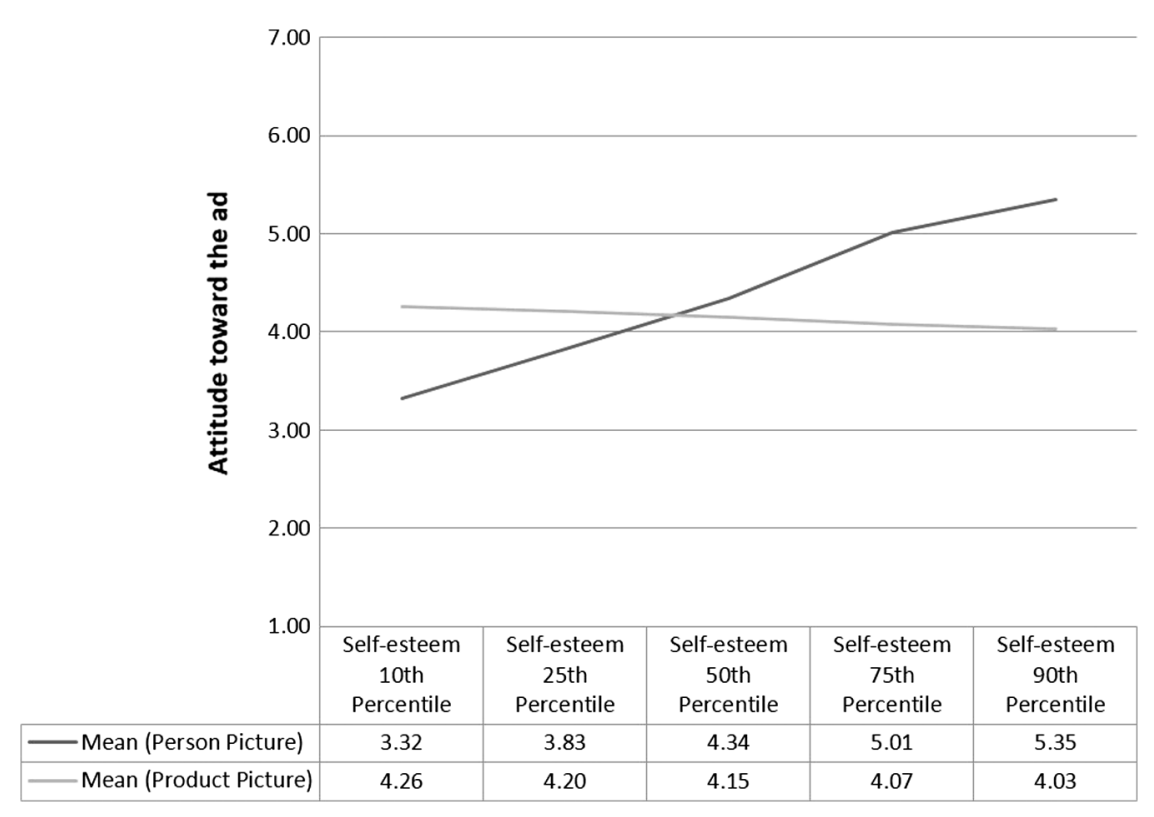

Fig. 1. Study 1 results. Effect of picture type and appearance self-esteem on attitudes toward the ad.

higher (CI: -.12 to .05). This finding supports H1a. Similarly, the person picture resulted in more favorable attitudes toward the ad compared to a product picture when appearance self-esteem was high (above 4.40, CI: -.64 to -1.10 ), but not when it was lower (CI: -1.28 to 3.42 ). This finding supports H1b. In sum, participants with high appearance self-esteem reported more favorable attitudes toward the ad that used a picture of an attractive person than toward the ad that used a picture of the product (white-strips package). The reverse was true for participants with low appearance self-esteem.

Moderated mediation analyses. Finally, we incorporated our proposed mediator (extent of self-related mental imagery) into the analysis and tested a model aimed to corroborate our moderated mediation hypothesis (H2) using Hayes (2013) PROCESS macro with 5000 bootstrapped samples (Preacher, Rucker, \& Hayes, 2007; see also cf. model 7 Hayes, 2012). H2 suggests a significant moderating effect of appearance self-esteem $(M o d)$ on the first path in the mediation (from picture type, $X$ to self-related mental imagery, $M e d$ ).

We found a significant interaction between picture type and appearance self-esteem on the extent of self-related mental imagery generated $(t=-3.65 ; p<.01)$. In other words, consistent with $\mathrm{H} 2$, the "first stage" of the mediation model $(X \rightarrow M e d)$ was moderated. Controlling for picture type, self-related mental imagery had a significant effect on attitudes toward the ad (Med $\rightarrow Y ; t=7.37 ; p<.01)$. Controlling for imagery, the direct effect of picture type on attitudes toward the ad was no longer significant $(t=-.97 ; p>.3)$. These series of observations confirm $\mathrm{H} 2$. To probe the moderation of the indirect effect, the bootstrap method also provides the estimates of the conditional indirect effect of $X$ on $Y$ through $M e d$ at various values of $\mathrm{Mod}$, and conducts inferential tests of the effect at those values. As Table 1 shows, we found a significant indirect effect of type of picture on attitudes toward the ad only in the first two and last two percentile groups (10th and 25th, 75th and 90th, respectively), in opposite directions, whereas the 50th percentile was not significant.

In general terms, this analysis shows that the ad with the picture of an attractive model generates greater self-related mental imagery for participants with high appearance selfesteem (compared to participants with low appearance selfesteem). Increased imagery, in turn, enhances their evaluations of the ad. The reverse is true for participants with low appearance self-esteem, for whom the picture of the product (white-strips package) generates greater self-related mental imagery, positively affecting their attitudes toward the ad.

Findings from study 1 support our hypotheses that appearance self-esteem moderates the effect of an ad's domain-relevant picture type on the extent of self-related mental imagery generated, thereby influencing attitudes toward the ad.

Table 1

Study 1 results: moderated mediation.

Conditional indirect effects of picture type on attitudes toward the ad at values of the moderator

\begin{tabular}{lrlcc}
\hline Moderator & Effect & \multicolumn{1}{l}{ SE } & Lower level CI & Upper level CI \\
\hline 10th percentile & .4400 & .1634 & .1479 & .7940 \\
25th percentile & .2217 & .1061 & .0258 & .4478 \\
50th percentile & .0034 & .0845 & -.1650 & .1687 \\
75th percentile & -.2876 & .1388 & -.5957 & -.0513 \\
90th percentile & -.4332 & .1814 & -.8413 & -.1301 \\
\hline
\end{tabular}


Ruling out alternative hypotheses

To rule out possible alternative explanations aside from those we controlled for in the second pretest, we present here a discussion of the control measures included in the study.

Brand anthropomorphism. One could argue that an ad's use of a person picture could humanize the brand more than the use of a product picture, drawing in the high-esteem individual, resulting in a systematic effect on the interaction. We used a two-item scale to measure brand anthropomorphism, asking about respondents' agreement with the following statements: "This brand is very much like a person" and "This is a very human-like brand" (Aggarwal \& McGill, 2007; $r=.84$, $p<.01)$. An ANCOVA with product type as the independent variable and brand anthropomorphism as the dependent variable, controlling for appearance self-esteem, revealed a non-significant main effect $(p>.3)$.

Abstract thinking. An alternative argument may be that the use of a person picture makes the ad more abstract in its benefits, thus becoming more attractive to a high-esteem individual. To indirectly control for this potential effect, we used a short version of the Behavior Identification Form (Vallacher \& Wegner, 1989), which was developed to assess people's construal level (i.e., the extent to which people's thinking is more abstract or concrete; $\alpha=.70$ ). An ANCOVA examined the impact of picture type on construal level, controlling for appearance self-esteem, and revealed a non-significant main effect $(p>9)$.

Self-ideal discrepancy. Another alternative explanation we tried to rule out was based on aspiration. A low-esteem individual may process the person picture from the perspective of who s/he would like to be. In this case, the score on self-related imagery would be low because the low-esteem individual would be thinking of a future state and not a current state. On the other hand, such a process would not apply to high-esteem individuals. To be able to represent this construct, we measured "self-ideal discrepancy" using a two-item scale: "To what extent is your current appearance different from your ideal appearance?" and "How large is the difference between your current and ideal appearance?" $(1=$ "Not at all different," 7 = "Extremely different;" $r=.85, p<.01$; Festinger, 1954). An ANCOVA showed a non-significant main effect of picture type on appearance-related self-discrepancy, controlling for appearance self-esteem $(p>.5)$.

Mood. Finally, we wanted to explore if the respondents' moods influenced their evaluations. To control for mood, we used a short version of the Mehrabian and Russell $(1974 ; \alpha=.84) \operatorname{mood}$ scale. An ANCOVA with picture type as the independent variable, controlling for mood and appearance self-esteem, revealed a non-significant effect of mood on attitudes toward the ad $(p>.1)$.

Overall, these supplementary analyses provide indirect support for study 1 results in demonstrating our proposed effects and process explanation. Next, in study 2, we use a different self-esteem domain, academic self-esteem. Doing so allows us to demonstrate greater applicability of our results and to broaden the scope of our findings beyond physical appearance and women. Also, whereas study 1 focused on the "extent" of self-related imagery, to provide complementary support for the proposed process, study 2 focuses on the "ease" with which it is generated.

\section{Study 2: Academic self-esteem and picture type}

Similar to study 1 , in study 2 , we investigate how the domain-relevant type of picture used in an ad affects attitudes toward the ad depending on domain-specific consumer selfesteem (H1). The suggested process is based on a differential generation of self-related mental imagery, with a focus on "ease" of imagery generation (H2). The domain focus of study 2 is academic self-esteem. Academic self-esteem relates to feelings of self-worth in terms of academic performance and intelligence (Woo \& Frank, 2000). It is noted as a basic motive (Crocker et al., 2003) and we can see multiple products being marketed to appeal to this specific domain of self-esteem, such as seminars, books, and lifelong educational programs.

As in study 1, we first report two pretests we ran in order to pick a domain-relevant product category and stimuli. Then, we present the main experiment.

\section{Pretests and stimuli}

\section{Pretest 1 - domain-relevant category}

Sixty-one participants from an online pool completed the first pretest, conducted to choose a product category relevant for the domain of academic self-esteem. Participants rated five different product/service categories offering education on presentation skills (books, certificate programs by educational institutions, seminars by professional organizations, online training programs, and membership to online blogs). We asked them to use a three-item scale to evaluate the perceived relevance of the categories for academic performance and intelligence (see Appendix 1 for the items; $\alpha=.88$ ). A repeated-measures analysis of variance test revealed a significant effect of product category on perceived relevance $(F(4,240)=15.56 ; p<.01)$. Planned contrasts between specific product categories showed that seminars by professional organizations had the highest perceived relevance $\left(M_{\text {Seminars }}=5.41\right)$, significantly greater than the average relevance of the other four categories $(F(1,60)=28.75$; $p<.01)$ and directionally larger than the second-highest-rated category of books $\left(M_{B o o k s}=5.22\right)$. Therefore, we chose to focus on this category.

\section{Pretest 2 - stimuli}

We ran a second pretest for selecting the ad stimuli. We created multiple print ads for a seminar on effective presentation skills by a fictitious MIB Marketing Institute. The ads displayed either a picture of a classroom or a picture of a person dressed professionally, in line with the domain focus of the main experiment. Because academic self-esteem concerns are not 
documented as being limited to a specific gender, we included both male and female models for the person-picture conditions. The pretest used a total of nine stimuli, with three different pictures for each category: classroom, female professional, and male professional.

Sixty-nine participants completed the pretest rating all nine ads (in random order) on relevance, realism, familiarity, perceived attractiveness, and perceived competence (see Appendix 1 for the items and Appendix 3b for means). The measures used were similar to those of the study 1 pretest with the addition of perceived competence, in line with the different domain focus on academic self-esteem. Between all nine stimuli, results revealed non-significant difference between two classroom and two person visuals on the tested dimensions (all $p$ 's $>.1)$. Thus, we selected those four pictures for the main experiment (see Appendix $2 b$ for the stimuli).

\section{Main experiment}

\section{Design, procedure, and measures}

Similar to study 1, the key independent variable, picture type (product vs. person), was manipulated between subjects. Picture version (product A vs. B, person A vs. B; see Appendix 2) was the second between-subjects factor, which was nested in picture type. Respondents' academic self-esteem level was included as a measured variable. One hundred and seventy-four participants from an online pool completed the experiment.

We presented the study as a series of unrelated tasks. Participants first responded to measures of academic selfesteem, presented as a "social psychology" survey (based on study 1 results, we expected no effect of measurement order for self-esteem on critical responses). Academic self-esteem was measured using a seven-item scale (Woo \& Frank, 2000) that included items such as "I believe that I have many academic/ professional strengths and abilities" and "When taking a test or when performing an important task, I am very confident that I will be successful" ( $\alpha=.90 ; 7$-point scales). We included a filler task between this first section of the study and the main task of ad exposure and evaluation.

The procedure for the main task was identical to study 1 , where participants viewed one of the ads and indicated their attitudes toward it on a five-item scale $(\alpha=.96)$. Next, we collected ratings on self-related mental imagery. Whereas study 1 focused on the "extent" of imagery generation, study 2 focused on the "ease" with which it is generated, in line with our complementary proposition per H2. Specifically, participants responded to the following questions: "As you reviewed the ad, how difficult or easy was it to create these images of yourself?" and "As you reviewed the ad, how quickly were these images of yourself aroused?" They then indicated their agreement with the statement "I had no difficulty imagining myself attending this seminar" (adapted from Petrova \& Cialdini, 2005; $\alpha=.87$ ). We concluded the study by collecting gender and education information and measures on mood.

\section{Results and discussion}

We first conducted a nested ANCOVA on attitudes toward the ad, with picture type (product vs. person) as the independent variable, picture version (classroom A vs. B; person A vs. B) as the nested factor, and respondents' academic self-esteem levels and gender as the covariates. We observed no significant main effects for picture type $(p>.2)$ or academic self-esteem $(p>.4)$. Furthermore, the effect of the nested factor of picture version (in picture type) was not significant $(p>.7)$. The final variable, gender, did not present a significant interaction with picture type $(p>.1)$.

Next, we utilized the Johnson-Neyman technique to check for the hypothesized interaction between picture type and academic self-esteem on attitude towards the ad (H1) and to test for the directional predictions of this moderation hypothesis (H1a and H1b). The technique showed two significant regions for the effect of picture type on attitudes toward the ad: for academic self-esteem values below 4.60 and above 6.00 . When academic self-esteem was low (below 4.60), the product picture resulted in significantly more favorable attitudes toward the ad compared to the person picture (CI: 4.81 to $.00)$, but not when academic self-esteem was higher (CI: .80 to $-1.19)$. This finding is consistent with H1a. Conversely, the person picture led to significantly more favorable attitudes toward the ad than a product picture when academic self-esteem was high (above 6.00 , CI: -1.29 to -.42 ), but not when it was lower (CI: -1.19 to .80$)$, corroborating $\mathrm{H} 1 \mathrm{~b}$ (see Fig. 2 for the data pattern).

In sum, participants with high academic self-esteem reported more positive attitudes toward the ad that depicted a competent person than toward the ad that used a picture of the product (classroom). The reverse was true for participants with low academic self-esteem.

Moderated mediation analyses. We tested the full moderated mediation model, again using the PROCESS macro (model 7) with 5000 bootstrapped samples. Replicating the results of study 1 , we observed a significant interaction between picture type and academic self-esteem on the fluency of mental imagery $(t=-3.94 ; p<.01)$. In other words, the "first stage" of the mediation model ( $X \rightarrow$ Med) was moderated, consistent with H2. Controlling for picture type, fluency of self-related mental imagery had a significant effect on attitude toward the ad $(M \rightarrow Y ; t=.11 ; p<.01)$. And controlling for imagery, picture type did not have a significant effect on attitudes $(p>.9)$. We also observed the estimates of the conditional indirect effect of $X$ on $Y$ through Med at various values of Mod. As Table 2 shows, we found a significant indirect effect of picture type on attitudes toward the ad only in the first two and in the last percentile groups, in opposite directions, whereas it was not significant in the percentile groups in the middle.

This analysis shows that the ad depicting a competent model generates more fluent self-related mental imagery for participants with high academic self-esteem (compared to participants with low academic self-esteem), thereby enhancing their evaluations of the ad. The opposite is true for participants with low academic self-esteem, for whom the 


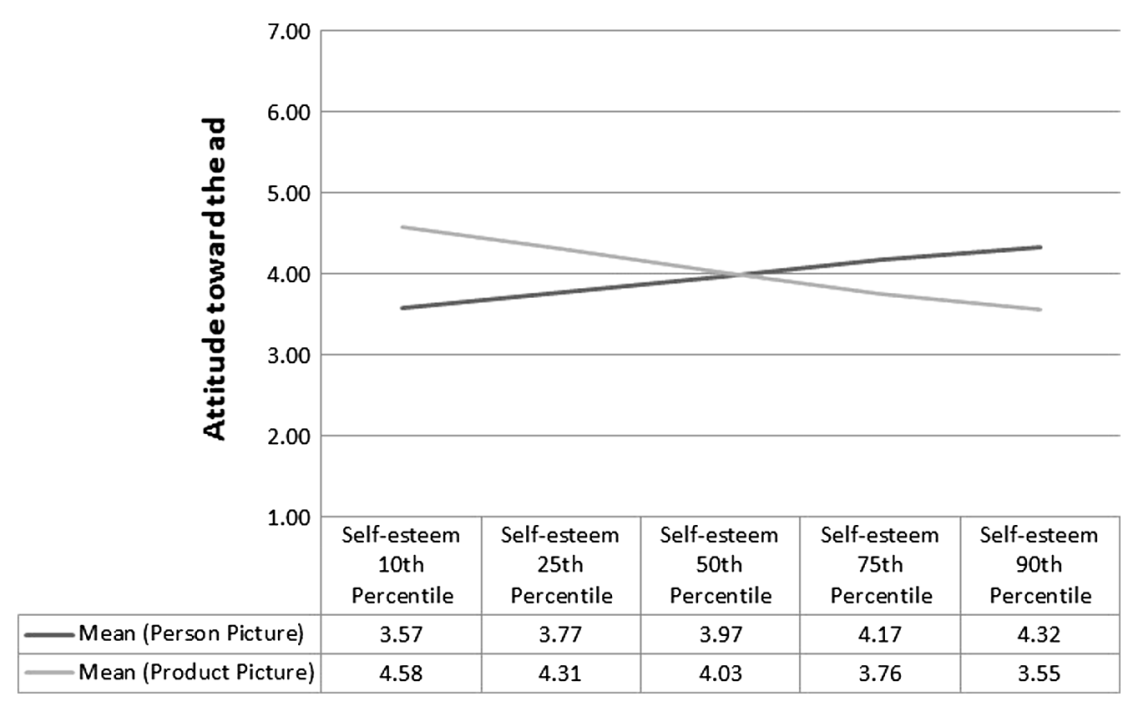

Fig. 2. Study 2 results. Effect of picture type and academic self-esteem on attitudes toward the ad.

picture of the product (classroom) generates more fluent self-related mental imagery, positively affecting their attitudes toward the ad.

Finally, we focused on the analysis of control variables. Education level was an important factor to control within the academic self-esteem domain of study 2 . When we included education as a covariate together with picture type and academic self-esteem in an ANCOVA test on attitudes toward the ad, neither its main effect nor its interaction with picture type was significant $\left(p^{\prime} s>.2\right)$. We also controlled for mood, and observed no significant effect $(p>.4)$.

In conclusion, study 2 results replicated the findings of study 1 in a different domain. All observations were in line with our proposition that academic self-esteem moderates the effect of an ad's picture type on the "ease" (fluency) with which self-related mental imagery is generated, thereby influencing attitudes toward the ad.

\section{General discussion}

Acknowledging the importance of self-referencing in advertising effectiveness and mental imagery, we incorporate

Table 2

Study 2 results: moderated mediation.

Conditional indirect effects of picture type on attitudes toward the ad at values of the moderator

\begin{tabular}{lcccc}
\hline Moderator & Effect & \multicolumn{1}{l}{ SE } & Lower level CI & Upper level CI \\
\hline 10th percentile & .5823 & .1956 & .2658 & 1.0224 \\
25th percentile & .3472 & .1350 & .1186 & .6471 \\
50th percentile & .1121 & .0998 & -.0808 & .3182 \\
75th percentile & -.1121 & .1161 & -.3696 & .0864 \\
90th percentile & -.2993 & .1544 & -.6436 & -.0336 \\
\hline
\end{tabular}

the effect of consumer self-evaluations into how consumers respond to the type of picture used in an ad. In two studies, we observe the hypothesized process, using two different domains of self-evaluation: appearance self-esteem and academic selfesteem. Our findings suggest that consumer self-evaluations are an important consideration in advertisement design, and, if incorporated carefully, can result in more favorable attitudes toward the ad through greater and more fluent self-related mental imagery.

More specifically, study 1 focuses on the domain of appearance-related products and self-esteem (and female subjects), and shows that for a teeth-whitening product, an ad depicting an attractive model is more liked by people with high appearance self-esteem, compared to an ad using a picture of a white-strips package - the product itself. For people with high appearance self-esteem, the picture of the attractive model generates greater self-related imagery (vs. the picture of the product), which mediates the effect on attitudes toward the ad. We observe the opposite for consumers with low appearance self-esteem, for whom the product picture (white-strips package) works better than the person picture (attractive model). These observations are in line with basic human motives of verifying and enhancing self-esteem, respectively (Dijksterhuis, 2004; Steele, 1988).

We note that our conceptual and methodological focus in this paper is not on general self-esteem, but on specific self-esteem pertaining to the domain of the product and the domain of the picture used in the ad that illustrates the benefits of the product. Accordingly, study 2 corroborates the findings of study 1 while broadening its scope by using academic self-esteem as its domain. This study also improves the applicability of our findings by including both genders as study participants and by focusing on a category with service implications (educational seminar). Indeed, for an educational seminar, an ad depicting a competent model is preferred by people with high academic self-esteem, 
compared to an ad using a picture of a classroom. For people with high academic self-esteem, the picture of the competent model evokes more fluent self-related imagery (vs. the picture of the product), thereby enhancing evaluations of the ad. We observe the contrary for consumers with low academic self-esteem.

Our concentration in this paper is on direct and controlled comparisons between product and person pictures. Therefore, our ad stimuli include minimal verbal information, with the message conveyed mainly through the visual. We believe this type of focus is justified considering the variety of products that are advertised primarily through visual means, such as clothing, perfumes, and services (Sojka \& Giese, 2006). However, interaction of product versus person pictures with textual systems should also be studied. Specifically, because person and product pictures both constitute concrete stimuli, a study of how they would interact with concrete or abstract verbal claims would be interesting.

An underlying assumption for our process explanation is that the persons depicted in advertising usually possess desirable characteristics (e.g., attractiveness, competence). We believe that this assumption is justified considering the prevalent use of highly desirable models in advertising across multiple domains (Pollay, 1985). Still, a study of model pictures with lower or moderate desirability would be another viable extension of this work. Whereas previous work on "idealized advertising images" has used such comparisons between person pictures (e.g., Martin \& Gentry, 1997), we believe that a further contribution would be possible through incorporating a comparison with product pictures.

We focused specifically on choosing pictures with desirable attributes for the domains we explored. However, pictures have many connotations and could trigger different comparisons with multiple domains of consumer self-esteem. For example, a consumer could have low academic self-esteem but high appearance self-esteem, and a picture may activate both of these specific self-esteem levels. We contend that our predicted effect will replicate when congruence is present between picture type and domain-specific self-esteem, as made particularly salient by the picture in the ad. In other words, a particular domain of self-esteem will be more dominant, in line with product category. However, more studies are needed to support this prediction.

Our work adds to the existing theories on advertising effectiveness and imagery in important ways. Pictures (images) are usually conceptualized as sensory analogs to objects in the environment (Scott, 1994). As such, the use of pictures in marketing communications has been characterized as generating advertiser-imposed imagery, as opposed to the richer and more relevant self-generated imagery (which can better be achieved through subtle techniques used as part of verbal communications). However, our work demonstrates that self-relevance in imagery can also be achieved through the use of pictures in advertising, when selected with a consideration of consumer self-perceptions.

Furthermore, previous research notes a need to further study types and individual properties of pictures for improved advertising effectiveness (Babin \& Burns, 1997; Pieters, Wedel, \& Batra, 2010). Our systematic focus on product versus person pictures constitutes progress in this direction. With the increased dominance of pictures in contemporary print advertising, as reviewed in our Introduction, similar investigations of typology and specific properties of pictures also warrant further research. This type of research should also incorporate a focus on individual consumer characteristics, as suggested by our findings.

\section{Appendix 1. Pretest measures}

\begin{tabular}{|c|c|c|}
\hline & Study 1 & Study 2 \\
\hline $\begin{array}{l}\text { Relevance of product } \\
\text { category* (pretest } 1)\end{array}$ & $\begin{array}{l}\text { Physical appearance and attractiveness }(\alpha=.93) \\
\text { - I think that_ can help me to be more good-looking } \\
\text { - I believe that __ is a product category relevant for } \\
\text { physical attractiveness } \\
\text { - I think __ can help a person become more attractive }\end{array}$ & $\begin{array}{l}\text { Academic and professional performance and competence } \\
(\alpha=.88) \\
\text { - I think that can help me to become more } \\
\text { successful academically and professionally } \\
\text { - I believe that is relevant for academic and } \\
\text { professional competence } \\
\text { - I think that can help a person become more } \\
\text { intellectually competent }\end{array}$ \\
\hline $\begin{array}{l}\text { Picture relevance for } \\
\text { domain* (pretest 2) }\end{array}$ & $\begin{array}{l}(r=.79 ; p<.01) \\
\text { - The picture used in the ad is relevant for the product } \\
\text { category } \\
\text { - The picture in the ad is appropriately chosen }\end{array}$ & $\begin{array}{l}(r=.87 ; p<.01) \\
\text { Same items as in study } 1 .\end{array}$ \\
\hline $\begin{array}{l}\text { Perceived realism (pretest 2) } \\
\text { Familiarity with picture* } \\
\quad \text { (pretest } 2 \text { ) }\end{array}$ & $\begin{array}{l}\text { - The picture in the ad was very unrealistic/very realistic } \\
(r=.83 ; p<.01) \\
\text { - The model in the picture (the product depicted here) is } \\
\text { very familiar to me }\end{array}$ & $\begin{array}{l}\text { Same items as in study } 1 . \\
(r=.81 ; p<.01) \\
\text { Same items as in study } 1 .\end{array}$ \\
\hline
\end{tabular}


Appendix (continued)

\begin{tabular}{|c|c|c|}
\hline & Study 1 & Study 2 \\
\hline $\begin{array}{l}\text { Perceived attractiveness* } \\
\quad \text { (pretest 2) }\end{array}$ & $\begin{array}{l}\text { - I have seen this model (a picture of this product) before in } \\
\text { the media } \\
(\alpha=.95) \\
\text { - I think the model depicted in the ad is very attractive } \\
\text { (I think the picture used in the ad is very pleasing) } \\
\text { - I like the way she looks (I like the picture used in the ad) } \\
\text { - I think she (the picture) is esthetically very appealing }\end{array}$ & $\begin{array}{l}(\alpha=.93) \\
\text { Same items as in study } 1 .\end{array}$ \\
\hline
\end{tabular}

*Measured with a 7-point agreement/disagreement scale.

\section{Appendix 2. Ad stimuli used in the studies}

Appendix 2a. Study 1 stimuli

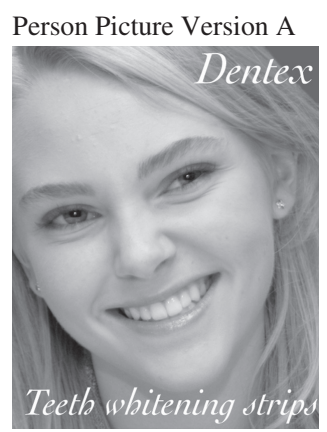

Person Picture Version B

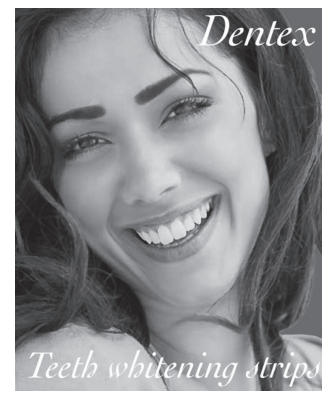

Person Picture Version C

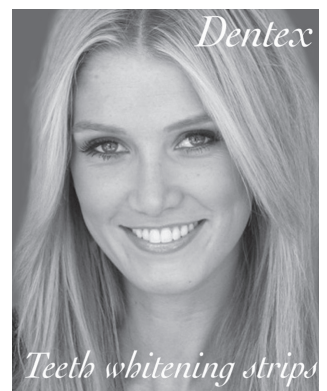

Product Picture Version A

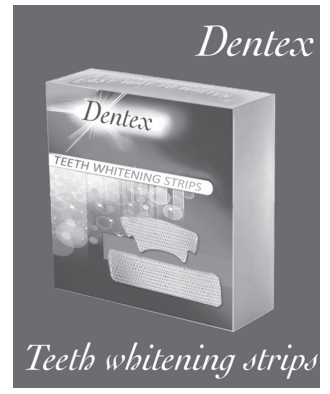

Product Picture Version B

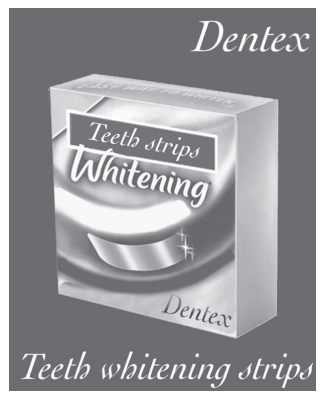

Product Picture Version C

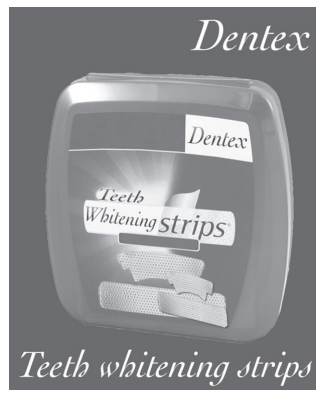


Appendix 2b. Study 2 stimuli

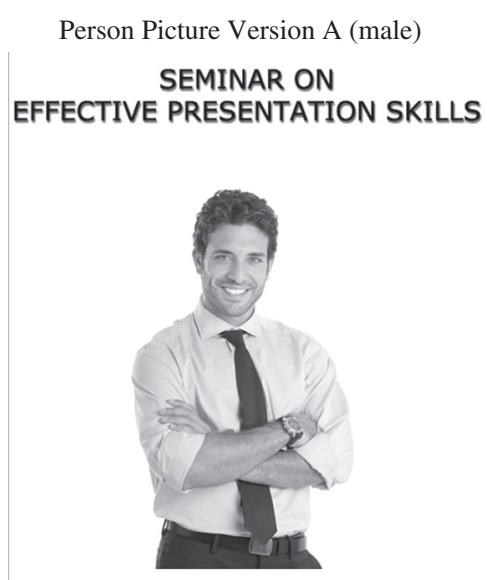

MIB Marketing Institute

Product Picture Version A SEMINAR ON EFFECTIVE PRESENTATION SKILLS

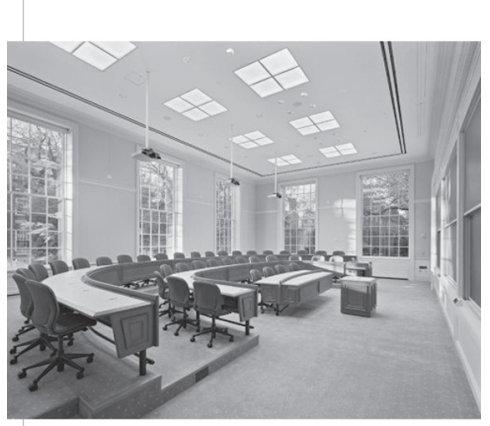

MIB Marketing Institute

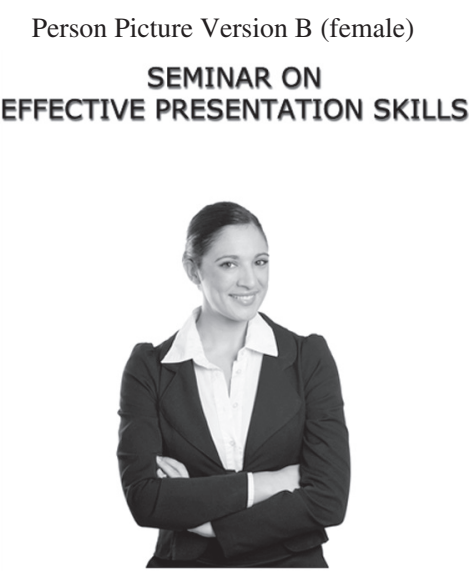

MIB Marketing Institute

Product Picture Version B

SEMINAR ON EFFECTIVE PRESENTATION SKILLS

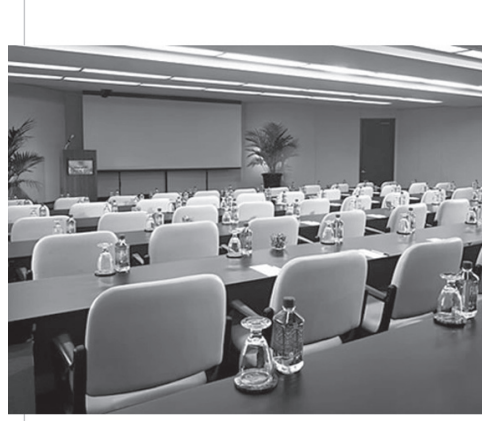

MIB Marketing Institute

\section{Appendix 3. Study stimuli characteristics (pretest results)}

Appendix 3a. Study 1 stimuli characteristics (pretest results)

\begin{tabular}{|c|c|c|c|c|c|c|c|c|c|c|}
\hline & \multicolumn{5}{|c|}{ Ads with a person picture (means for each version) } & \multicolumn{5}{|c|}{ Ads with a product picture (means for each version) } \\
\hline & $\overline{\mathrm{A}}$ & $\mathrm{B}$ & $\mathrm{C}$ & $*$ & $*$ & $\overline{\mathrm{A}}$ & $\mathrm{B}$ & $\mathrm{C}$ & $*$ & $*$ \\
\hline Picture relevance for domain & 5.10 & 5.54 & 5.48 & 4.29 & 5.02 & 5.95 & 5.46 & 5.80 & 5.27 & 5.27 \\
\hline Perceived realism & 5.35 & 5.39 & 5.46 & 4.62 & 4.62 & 5.89 & 5.29 & 5.68 & 5.00 & 3.87 \\
\hline Familiarity with picture & 2.58 & 2.35 & 2.48 & 1.87 & 2.37 & 2.75 & 2.69 & 2.60 & 2.67 & 2.75 \\
\hline Perceived attractiveness & 5.44 & 5.96 & 5.95 & 4.12 & 5.77 & 5.50 & 5.48 & 5.17 & 3.75 & 4.11 \\
\hline
\end{tabular}

Note: Bolded text indicates stimuli used in study 1.

Versions marked with * indicate stimuli included in the pretest, but not selected for study 1 . 
Appendix 3b. Study 2 stimuli characteristics (pretest results)

\begin{tabular}{|c|c|c|c|c|c|c|c|c|c|}
\hline & \multicolumn{3}{|c|}{$\begin{array}{l}\text { Ads with a male model picture } \\
\text { (means) }\end{array}$} & \multicolumn{3}{|c|}{$\begin{array}{l}\text { Ads with a female model picture } \\
\text { (means) }\end{array}$} & \multicolumn{3}{|c|}{$\begin{array}{l}\text { Ads with a classroom picture } \\
\text { (means) }\end{array}$} \\
\hline & $\overline{\mathrm{A}}$ & * & $*$ & $\overline{\mathrm{B}}$ & $*$ & * & $\overline{\mathrm{A}}$ & B & $*$ \\
\hline Perceived realism & 5.33 & 4.82 & 4.65 & 5.26 & 4.62 & 4.65 & 5.40 & 5.12 & 5.66 \\
\hline $\begin{array}{l}\text { Familiarity with } \\
\text { picture }\end{array}$ & 2.08 & 1.80 & 1.81 & 2.07 & 2.04 & 1.86 & 2.36 & 2.15 & 2.15 \\
\hline $\begin{array}{l}\text { Perceived } \\
\text { competence }\end{array}$ & 5.04 & 4.63 & 4.42 & 5.44 & 4.73 & 4.17 & 4.81 & 5.14 & 4.49 \\
\hline
\end{tabular}

Note: Bolded text indicates stimuli used in study 2.

Versions marked with * indicate stimuli included in the pretest, but not selected for study 2 .

\section{References}

Aggarwal, P., \& McGill, A. L. (2007). Is that car smiling at me? Schema congruity as a basis for evaluating anthropomorphized products. Journal of Consumer Research, 34(4), 468-479.

Allport, G. W. (1937). Personality: A psychological interpretation. New York: Holt.

Aydinoglu, N. Z., \& Krishna, A. (2012). Imagining thin: Why vanity sizing works. Journal of Consumer Psychology, 22(4), 565-572.

Babin, L. A., \& Burns, A. C. (1997). Effects of print ad pictures and copy containing instructions to imagine on mental imagery that mediates attitudes. Journal of Advertising, 26(3), 33-44.

Bauer, D. J., \& Curran, P. J. (2005). Probing interactions in fixed and multilevel regression: Inferential and graphical techniques. Multivariable Behavioral Research, 40(3), 373-400.

Bolls, P. D., \& Muehling, D. D. (2007). The effects of dual-task processing on consumers' responses to high- and low-imagery radio advertisements. Journal of Advertising, 36(4), 35-47.

Bone, P. F., \& Ellen, P. S. (1992). The generation and consequences of communication-evoked imagery. Journal of Consumer Research, 19(1), 93-104.

Bower, A. B. (2001). Highly attractive models in advertising and the women who loathe them: The implications of negative affect for spokesperson effectiveness. Journal of Advertising, 30(3), 51-63.

Burnkrant, R. E., \& Unnava, H. R. (1995). Effects of self-referencing on persuasion. Journal of Consumer Research, 22(1), 17-26.

Burns, A. C., Biswas, A., \& Babin, L. A. (1993). The operation of visual imagery as a mediator of advertising effects. Journal of Advertising, 22(2), 71-85.

Childers, T. L., \& Houston, M. J. (1984). Conditions for a picture superiority effect on consumer memory. Journal of Consumer Research, 11(2), 643-654.

Coopersmith, S. (1990). Self-esteem inventories. Palo Alto, CA: Consulting Psychologists Press.

Crandall, R. (1973). The measurement of self-esteem and related constructs. In J. P. Robinson, \& P. R. Shaver (Eds.), Measures of social psychological attitudes (pp. 45-167). Ann Arbor, MI: Institute for Social Research.

Crocker, J., Luhtanen, R. K., Cooper, M. L., \& Bouvrette, A. (2003). Contingencies of self-worth in college students: Theory and measurement. Journal of Personality and Social Psychology, 85(5), 894-908.

Debevec, K., \& Romeo, J. B. (1992). Self-referent processing in perceptions of verbal and visual commercial information. Journal of Consumer Psychology, 1(1), 83-102.

Dijksterhuis, A. (2004). I like myself but I don't know why: Enhancing implicit self-esteem by subliminal evaluative conditioning. Journal of Personality and Social Psychology, 86(2), 345-355.

Edell, J. A., \& Staelin, R. (1983). The information processing of pictures in print advertisements. Journal of Consumer Research, 10(1), 45-61.

Erikson, E. H. (1959). Identity and the life cycle: Selected papers. Psychological Issues, 1, 5-165.

Festinger, L. (1954). A theory of social comparison processes. Human Relations, $7(2), 117-140$.
Hayes, A. F. (2012). PROCESS: A versatile computational tool for observed variable mediation, moderation, and conditional process modeling [White paper]. Retrieved from http://www.afhayes.com/public/process2012.pdf

Hayes, A. F. (2013). Introduction to mediation, moderation, and conditional process analysis: A regression-based approach. New York: Guilford Press.

Hayes, A. F., \& Matthes, J. (2009). Computational procedures for probing interactions in OLS and logistic regression: SPSS and SAS implementations. Behavioral Research Methods, 41, 924-936.

Heartherton, T. F., \& Polivy, J. (1991). Development and validation of a scale for measuring self-esteem. Journal of Personality and Social Psychology, 60(6), 895-910.

Johnson, P. O., \& Neyman, J. (1936). Tests of certain linear hypotheses and their applications to some educational problems. Statistical Research Memoirs, 1, $57-93$.

Kisielius, J., \& Sternthal, B. (1984). Detecting and explaining vividness effects in attitudinal judgments. Journal of Marketing Research, 21(1), 54-64.

Lockwood, P., \& Kunda, Z. (1997). Superstars and me: Predicting the impact of role models on the self. Journal of Personality and Social Psychology, 73(1), 91-103.

Lutz, K. A., \& Lutz, R. J. (1978). Imagery-eliciting strategies: Review and implications of research. Advances in Consumer Research, 5(1), 611-620.

Lynch, J., \& Schuler, D. (1994). The matchup effect of spokesperson and product congruency: A schema theory interpretation. Psychology and Marketing, 11(5), 417-445.

MacInnis, D. J., \& Jaworski, B. J. (1989). Information processing from advertisements: Toward an integrative framework. Journal of Marketing, 53(4), $1-23$.

MacInnis, D. J., \& Price, L. L. (1987). The role of imagery in information processing: Review and extensions. Journal of Consumer Research, 13(4), $473-491$.

Marsh, H. W. (1993). Relations between global and specific domains of self: The importance of individual importance, certainty, and ideals. Journal of Personality and Social Psychology, 65(5), 975-982.

Martin, M. C., \& Gentry, J. W. (1997). Stuck in the model trap: The effects of beautiful models in ads on female pre-adolescents and adolescents. The Journal of Advertising, 26(2), 19-33.

Martin, B. A. S., Veer, E., \& Pervan, S. J. (2007). Self-referencing and consumer evaluations of larger-sized female models: A weight locus of control perspective. Marketing Letters, 18, 197-209.

McQuarrie, E. F. (2007). Differentiating the pictorial element in advertising: A rhetorical perspective. In M. Wedel, \& R. Pieters (Eds.), Visual marketing (pp. 91-112). New York: Lawrence Erlbaum Associates.

Mehrabian, A., \& Russell, A. (1974). An approach to environmental psychology. Cambridge, Mass: MIT Press.

Meyers-Levy, J., \& Peracchio, L. A. (1996). Moderators of the impact of selfreference on persuasion. Journal of Consumer Research, 22(4), 408-423. 
Peracchio, L. A., \& Meyers-Levy, J. (2005). Using stylistic properties of ad pictures to communicate with consumers. Journal of Consumer Research, 32(1), 29-40.

Petrova, P. K., \& Cialdini, R. B. (2005). Fluency of consumption imagery and the backfire effects of imagery appeals. Journal of Consumer Research, 32(3), $442-452$.

Pieters, R., Wedel, M., \& Batra, R. (2010). The stopping power of advertising: Measures and effects of visual complexity. Journal of Marketing, 74(5), 48-60.

Pollay, R. W. (1985). The subsiding sizzle: A descriptive history of print advertising, 1900-1980. Journal of Marketing, 49(3), 24-37.

Preacher, K. J., Rucker, D. D., \& Hayes, A. F. (2007). Addressing moderated mediation hypotheses: Theory, methods, and prescriptions. Multivariate Behavioral Research, 42(1), 185-227.

Rosen, J. C., \& Gross, J. (1987). Prevalence of weight reducing and weight gaining in adolescent girls and boys. Health Psychology, 6(2), 131-147.

Rosenberg, M., Schoenbach, C., Schooler, C., \& Rosenberg, F. (1995). Global self-esteem and specific self-esteem: Different concepts, different outcomes. American Sociological Review, 60(1), 141-156.

Rossiter, J. R., \& Percy, L. (1980). Attitude change through visual imagery in advertising. Journal of Advertising, 9(2), 10-16.

Schwarz, N. (2004). Metacognitive experiences in consumer judgment and decision making. Journal of Consumer Psychology, 14(4), 332-348.

Schwarz, N., Bless, H., Strack, F., Klumpp, G., Rittenauer-Schatka, H., \& Simons, A. (1991). Ease of retrieval as information: Another look at the availability heuristic. Journal of Personality and Social psychology, 61(2), 195.

Scott, L. M. (1994). Images in advertising: The need for a theory of visual rhetoric. Journal of Consumer Research, 21(2), 252-273.

Sojka, J. Z., \& Giese, J. L. (2006). Communicating through pictures and words: Understanding the role of affect and cognition in processing visual and verbal information. Psychology and Marketing, 23(12), 995-1014.

Spiller, S. A., Fitzsimons, G. J., Lynch, J. G., \& McClelland, G. H. (2013) Spotlights, floodlights, and the magic number zero: Simple effects tests in moderated regression. Journal of Marketing Research, 50(2), 277-288.

Steele, C. M. (1988). The psychology of self-affirmation: Sustaining the integrity of the self. In L. Berkowitz (Ed.), Advances in experimental social psychology (pp. 261-302). New York: Academic Press.

Swann, W. B., \& Pelham, Brett (2002). Who wants out when the going gets good? Psychological investment and preference for self-verifying college roommates. Self and Identity, 1(3), 219-233.

Swann, W., Pelham, B. W., \& Krull, D. S. (1989). Agreeable fancy or disagreeable truth? Reconciling self-enhancement and self-verification. Journal of Personality and Social Psychology, 57(5), 782-791.

Vallacher, R. R., \& Wegner, D. M. (1989). Levels of personal agency: Individual variation in action identification. Journal of Personality and Social Psychology, 57(4), 660.

van Gisbergen, M. S., Ketelaar, P. E., \& Beentjes, J. (2004). Changes in advertising language? A content analysis of magazine advertisements in 1980 and 2000. In P. Neijens, C. Hess, B. van den Putte, \& E. Smit (Eds.), Content and media factors in advertising (pp. 22-37). Amsterdam: Spinhuis Publishers.

Woo, T. O., \& Frank, N. (2000). Academic performance and perceived validity of grades: An additional case for self-enhancement. The Journal of Social Psychology, 140(2), 218-226.

Yang, X., Zhang, J., \& Peracchio, L. A. (2010). Understanding the impact of self-concept on the stylistic properties of images. Journal of Consumer Psychology, 20(4), 508-520. 